\title{
Saberes dos cidadãos e saber político
}

Citizen Knowledge and Political Knowledge

Du savoir d'usage au métier de citoyen

\section{Yves Sintomer}

\section{CpenEdition}

\section{Journals}

Edição electrónica

URL: http://journals.openedition.org/rccs/4185

DOI: $10.4000 /$ rccs. 4185

ISSN: 2182-7435

\section{Editora}

Centro de Estudos Sociais da Universidade de Coimbra

\section{Edição impressa}

Data de publição: 1 Dezembro 2010

Paginação: 135-153

ISSN: 0254-1106

Refêrencia eletrónica

Yves Sintomer, "Saberes dos cidadãos e saber político », Revista Crítica de Ciências Sociais [Online], 91 | 2010, colocado online no dia 16 outubro 2012, criado a 19 abril 2019. URL : http:// journals.openedition.org/rccs/4185; DOI : 10.4000/rccs.4185 


\section{YVES SINTOMER}

\section{Saberes dos cidadãos e saber político"}

Nos processos participativos contemporâneos, expressões como "saber do cidadão", "saber comum" ou "saber do utilizador" são, hoje em dia, excessivamente utilizadas. Este artigo esclarece o âmbito destas expressões, ao analisar, sucessivamente, três conjuntos epistémicos aplicáveis às dinâmicas de participação: a razão comum, a expertise do cidadão e o saber político. $\mathrm{O}$ artigo discute os desafios políticos deste apoio reivindicado nessas formas específicas de saber e contribui para renovar a oposição clássica entre teorias elitistas e teorias participativas da democracia. Embora a redução do saber dos profissionais da política a um saber político mais geral seja improvável, será que a dependência dos saberes dos cidadãos não é susceptível de contribuir para a revitalização da política no seu todo?

Palavras-chave: democracia participativa; processos participativos; saberes; teoria política; tomada de decisão.

Nos processos participativos contemporâneos, expressões como "saber do cidadão", "saber comum" ou "saber do utilizador" são, hoje em dia, usadas em excesso pelos responsáveis políticos e associativos, assim como por instituições (por exemplo, fundações, universidades, centros de estudos). Neste artigo, pretendemos esclarecer de forma analítica o que estas expressões contemplam, analisar os desafios políticos deste apoio reivindicado por uma forma específica de saber e questionar qual a contribuição deste debate para a oposição clássica entre teorias elitistas e teorias participativas da democracia, tão bem resumida por duas citações de John Dewey e Joseph Schumpeter, de 1920 e 1940, respectivamente. O primeiro fazia o elogio do contributo epistemológico da participação e escrevia:

A pessoa que calça o sapato é que sabe se the aperta ou onde lhe aperta, embora o sapateiro qualificado possa saber melhor como resolver o problema [...] Uma classe

* Este artigo retoma, com algumas alterações, uma comunicação apresentada nas jornadas do CIERA "Y a-t-il un 'savoir citoyen' mobilisable dans la démocratie participative?" (Paris, 27 de Fevereiro de 2006) e publicada em Raisons politiques, 31, Agosto de 2008, p. 115-134. 
de experts está inevitavelmente tão afastada do interesse comum, que se torna numa classe com interesses particulares e um saber privado - o que, no que respeita às questões sociais, equivale a um não-saber. (Dewey, 1954: 207)

O segundo respondeu-lhe indirectamente com uma perspectiva radicalmente céptica a respeito do "saber do cidadão":

O cidadão comum cai num nível inferior de desempenho mental logo que entra no campo político. Argumenta e analisa de uma forma que reconheceria imediatamente como infantil na esfera dos seus interesses reais. Torna-se num primitivo. O seu raciocínio torna-se associativo e afectivo. (Schumpeter, 1946: 262)

Tal debate não é, de resto, próprio da política. Para mencionar apenas um dos exemplos mais célebres, Michel Foucault defendeu, em 1976, no Collège de France, a opinião de que os "saberes subjugados" diziam sobretudo respeito a

toda uma série de saberes que se constatou serem desqualificados como saberes não conceptuais, como saberes insuficientemente elaborados, saberes ingénuos, saberes hierarquicamente inferiores, saberes abaixo do nível de conhecimento ou de cientificidade necessário. E é a reaparição destes saberes inferiores, destes saberes não qualificados, destes saberes até mesmo desqualificados [...], é este saber que eu denominaria de "saber do povo", e que não é, de todo, um saber comum, um bom senso, mas, pelo contrário, um saber particular, um saber local, um saber diferencial, incapaz de ser unânime e que apenas deve a sua força ao gume com que enfrenta todos o que o rodeiam, é mediante a reaparição destes saberes locais das pessoas, destes saberes desqualificados, que se faz a crítica. (1994: 164)

Por seu turno, Georges Bataille dedicou uma parte do seu trabalho a estudar o "não-saber". ${ }^{1}$ Por falta de espaço, não nos debruçaremos, no entanto, sobre uma comparação entre os "saberes subjugados" na política e fora dela. Tentaremos estudar as diferentes faces dos "saberes dos cidadãos" ao longo de três partes, que correspondem a três conjuntos de "saberes" aplicáveis aos movimentos participativos: a razão comum, a expertise dos cidadãos e o saber político. ${ }^{2}$

\footnotetext{
${ }^{1}$ Cf. M. Pic (org.), Figures du non-savoir, Le genre humain. Paris: Seuil, 2011 (no prelo).

${ }^{2} \mathrm{H}$. Nez complexificou e colocou em contexto empírico a presente tipologia na sua tese de doutoramento intitulada "Les savoirs citoyens dans l'urbanisme participatif. Regards croisés sur les expériences de Paris et Cordoue” (Université de Paris 8, Paris, Novembro de 2010).
} 


\section{A razão comum}

Numa primeira problemática, a noção de "saber do cidadão" e termos equivalentes evocam a ideia de uma razão comum, acessível a todas as pessoas. Assim, podem distinguir-se duas variantes, que designam dinâmicas muito diferentes no que respeita à justificação da participação dos cidadãos em processos de tomada de decisão. O "saber do utilizador", aquele que a citação de John Dewey permite que constitua um verdadeiro paradigma, é a noção mais usada. Ela é advogada nas perspectivas sobre auto-gestão, mas também tem sido, desde há alguns anos, fortemente valorizada na onda de reformas que se inscrevem no espírito do New Public Management. Este último introduz transformações que seguem uma lógica mercantil, modificações internas ao nível do funcionamento da administração e das relações que esta estabelece com os seus utilizadores-clientes, agora admitidos no círculo dos stakeholders. A integração do saber do utilizador é um recurso fundamental e sustenta um argumento bastante forte para a participação, por vezes admitida pelas teorias elitistas. De acordo com a visão neoliberal clássica, defendida, por exemplo, na linha de Friedrich Hayek, cada um conhece os seus interesses enquanto utilizador. O conhecimento deste saber permite adaptar e melhorar a oferta de políticas públicas, de modo a que estas correspondam melhor às necessidades das pessoas às quais se destinam. Nesta perspectiva, os inquéritos de satisfação ou os painéis de clientes são instrumentos preciosos, importados das técnicas de marketing do sector privado. De acordo com uma visão mais comunicativa, é necessário um debate para que as várias necessidades expressas produzam um saber explorável: o diálogo entre os técnicos e as pessoas em causa (tais como inquilinos, habitantes) ou os seus representantes, por exemplo, nos conselhos de bairro, permite, através de uma discussão pública, uma progressiva clarificação das necessidades mediante a emergência de um conhecimento partilhado entre cidadãos, e entre cidadãos e experts.

A dependência do saber do utilizador inscreve-se no paradigma da proximidade, entendido numa tripla acepção. Desde logo, proximidade geográfica porque o saber do utilizador é imediatamente local ou microssectorial. A este nível, a participação vai de mão dada com os serviços públicos mais acessíveis, por exemplo, graças à aplicação das antenas de bairro ou à generalização dos processos na Internet. Assim, o local é o coração e o trampolim da democracia de uma forma geral, uma ideia já presente em John Dewey (1954: 213): "A democracia deve começar em casa, e essa casa é a comunidade de vizinhos". A proximidade também é a da comunicação entre decisores e utilizadores, como aquela que é abarcada pela "pessoa eleita por um determinado círculo" ou o técnico que gere "em contacto com o terreno", 
ao invés de estar fechado no seu gabinete. O saber do utilizador enriquece o saber técnico, como o refere a segunda parte da citação inicial de John Dewey. Por fim, a proximidade assume, por vezes, o sentido de uma semelhança sociológica entre decisores e munícipes. $\mathrm{O}$ argumento foi bem sintetizado pelo antigo Presidente Jacques Chirac no debate sobre a igualdade, quando afirmou que a representação dos franceses deve ser "à imagem de França". ${ }^{3}$ Trata-se de uma velha ideia, invocada, em especial, pelo movimento operário de meados do século XIX, quando se debatiam as candidaturas dos trabalhadores às eleições:

O trabalhador conhece as suas necessidades e os seus recursos. Quem melhor para nos indicar aquilo de que necessita ou que deseja? As pessoas em altos cargos imaginam que só elas têm o poder para curar as pragas sociais e que só elas dominam a ciência necessária, mas à menor aplicação que fazem desta, conseguem meter o emplastro ao lado do mal. (apud Rosanvallon, 1998: 84)

Esta perspectiva radicaliza o paradigma de Dewey, sugerindo que, para saber o que o povo sabe e a forma ideal de resolver os seus problemas, é necessário ser semelhante a ele - podendo este argumento ser utilizado com outros grupos, como as mulheres (Manin, 1995; Sintomer, 2007).

Ao mesmo tempo, o saber do utilizador tende a circunscrever a participação na proximidade ou na esfera sectorial, o que permite a sua integração nas teorias elitistas, sendo que Joseph Schumpeter admite, por exemplo, que o raciocínio dos cidadãos pode, nos assuntos locais, ascender até à esfera pública (1946: 260). Tal facto não retira nada à sua argumentação de fundo: quando se troca o próximo por questões mais globais, seria ridículo contar com este. É por este motivo que os cidadãos, que são geralmente razoáveis no seu ofício ou nos seus afazeres quotidianos e, por extensão, naqueles que lhes dizem directamente respeito enquanto utilizadores, perdem todo o sentido prático quando se trata de questões gerais (Joseph Schumpeter menciona as questões de política macroeconómica ou os negócios estrangeiros). A este respeito, a máxima elitista reformulada numa retórica republicana poderia ser: "Só se governa bem à distância, mas só se gere bem na proximidade [porque] numa boa gestão democrática, a distância permite evitar confundir a expressão dos interesses privados com os interesses gerais, assim como ceder às pressões conjunturais". ${ }^{4}$ As teses participativas que se

\footnotetext{
${ }^{3}$ Citado por Marie-Jo Zimmermann, acta dos debates da Assembleia Nacional sobre a paridade, $3^{a}$ sessão de 15 de Dezembro de 1998.

${ }^{4}$ Jean Espilondo, deputado socialista, acta dos debates da Assembleia Nacional sobre a democracia de proximidade, $2^{a}$ sessão de 14 de Junho de 2001.
} 
estribam exclusivamente, ou essencialmente, no saber do utilizador têm dificuldades em responder a esta crítica.

No entanto, noutros dispositivos participativos, não é apenas na sua dimensão de utilização que a razão comum dos cidadãos é convocada e a estes últimos é-lhes pedido que exerçam o seu "bom senso". Este termo remete para uma faculdade comum de julgamento, a "capacidade de fazer um bom julgamento, sem paixão, na presença de problemas que não podem ser solucionados através da razão científica". ${ }^{5}$ Ele aproxima-se do "senso comum", ou seja, de "uma maneira de julgar e de agir comum a todos os homens", ${ }^{6}$ mas sem o lado pejorativo por vezes atribuído a este último conceito quando é utilizado como sinónimo de "pré-noção", que seria conveniente ultrapassar. Este saber não sistemático e, predominantemente, desinteressado ("julgar sem paixão") é tradicionalmente utilizado nos júris dos tribunais. De facto, o advento das revoluções democráticas modernas trouxe uma dimensão de saber do utilizador através da proximidade social que pressupunha o julgamento por pares: era pelo facto de conhecerem o contexto da acção que os jurados podiam tomar uma decisão justa, sendo que só mais tarde é que esta proximidade social entre o réu e os jurados passou a ser cada vez mais questionada. ${ }^{7}$ Contudo, este "saber social" só se torna relevante na medida em que se articula com uma capacidade de raciocínio comum. É esta que é decisiva: o julgamento dos jurados não assenta numa determinada competência técnica, mas sim no exercício da sua razão subjectiva. Hegel sintetiza com rigor o que esteve no âmago do raciocínio dos legisladores progressistas da época. A sua ideia fundamental é a de que uma parte, pelo menos, do julgamento penal, "o conhecimento acerca do caso na sua singularidade imediata", constitui "um conhecimento que está ao alcance de qualquer homem culto". Assim, está acessível aos leigos, ou, pelo menos, aos mais qualificados dentro destes. Centrando-se nas especificidades, apoiando-se menos nas provas lógicas rigorosas do que na "convicção subjectiva e consciência”, a decisão que representa a qualificação do acto e a constatação do facto não pertence à universalidade (Hegel, 1986: $\$ 227$ ). Esta distingue-se do julgamento que aplica a lei ao facto particular, mas mais ainda do direito em si, que faz parte, por sua vez, do universal.

$\mathrm{Na}$ esfera política, este senso comum é tradicionalmente utilizado nos tribunais de júri e nas conferências de consensos, nas quais os cidadãos comuns são chamados a emitir uma opinião (ou seja, em certos casos, a tomarem

\footnotetext{
${ }^{5}$ Le petit Robert. Paris: Dictionnaires Le Robert, 2007.

${ }^{6}$ Ibidem.

${ }^{7}$ Cf. Hegel, Cours du semestre d'hiver 1818-1819; Droit naturel et droit politique, $\mathbb{S} 111$, em La société civile bourgeoise (1975); e Abramson, 2003.
} 
decisões) sobre questões em que não estão necessariamente envolvidos de forma directa. O recurso aos sorteios é, nesta perspectiva, uma garantia privilegiada da imparcialidade do julgamento dos jurados (Sintomer, 2007). Pode inclusivamente constituir uma alternativa às associações: a participação de "cidadãos comuns" pode, por isso, ser uma arma contra a sociedade civil organizada, suspeita de ser detentora de interesses particulares. Assim, o espírito de tais dispositivos pode afastar-se substancialmente do saber do utilizador e até mesmo opor-se a este, em certos casos.

A fim de ser aplicado, o bom senso necessita de suficientes informações, debates contraditórios (ou, pelo menos, pluralistas), que permitam a troca de argumentos e momentos de introspecção pessoal (em que cada um toma a sua decisão com base no melhor que sabe). Assim, está intimamente relacionado com a reflexão, que possibilita a criação de uma opinião esclarecida. No entanto, esta pode ser concebida como fundamentalmente comunicativa e dialogal, como é o caso nas problemáticas inspiradas em Jürgen Habermas, ou, pelo contrário, como mais ou menos monológica, na linha de John Rawls e, mais ainda, de Jean-Jacques Rousseau (1964: II, 3), que afirmou que "para que fique claramente manifesta a expressão da vontade geral, importa que não haja sociedade parcial no Estado e que cada cidadão não tenha outra opinião que não seja a sua”.

Sem este bom senso, a própria noção de democracia - a ideia de que todas as pessoas têm o direito de participar na definição dos assuntos comuns, mesmo que só através da eleição dos representantes - estaria vazia de sentido. Contudo, uma dúvida paira sobre esta noção: o bom senso é uma faculdade que pertence a todos os indivíduos ou é necessário um determinado nível cultural para que essa capacidade possa ser plenamente aplicada? Se todas as pessoas são, normalmente, dotadas de bom senso, não o terão umas mais que outras? O artigo sexto da Declaração dos Direitos do Homem e do Cidadão de 1789 afirma, por exemplo, que "todos os cidadãos [...] têm igualmente acesso a todas as dignidades, lugares e empregos públicos, segundo a sua capacidade, e sem outra distinção que não seja a das suas virtudes e talentos". Ora, o argumento relativo às capacidades foi utilizado durante muito tempo para privar do direito de voto e para excluir dos tribunais de júri os pobres e as mulheres (Sintomer, 2007). Hoje em dia, o bom senso é inegavelmente reconhecido nas reuniões públicas, e os cidadãos munidos de um capital cultural superior ou, simplesmente, habituados a usar a linguagem que mais convém em tais instâncias, estão mais aptos a fazer-se ouvir do que os outros, visto que dominam melhor as regras da "gramática da discussão pública” (Cefaï e Trom, 2001). Geralmente, a palavra dos jovens, dos membros das camadas populares e dos descendentes de imigrantes goza 
de uma legitimidade bastante frágil e essas pessoas tendem a exprimir-se menos frequentemente do que as outras.

Apesar destas lacunas, o crescente recurso ao "bom senso" inscreve-se numa dinâmica simbólica mais vasta de igualização de estatutos, na acepção que Tocqueville confere a este termo: não uma redução de desigualdades de facto, em especial socioeconómicas, mas sim uma igualdade simbólica que tende a conceder a todos os cidadãos uma igual dignidade de princípio. ${ }^{8}$

\section{A expertise do cidadão}

O "saber do cidadão" não se cinge a estas formas de razão comum. $\mathrm{Na}$ retórica participativa, por vezes, surge a expressão "expertise do utilizador": tratar-se-ia de reconhecer aos cidadãos um estatuto de "experts do seu quotidiano". O termo joga com o sentido original da palavra, oriunda do latim. O adjectivo "expert" significa "o que se torna hábil através da experiência", "quem, através da experiência, adquiriu uma grande habilidade". ${ }^{10}$ No entanto, a palavra evoluiu historicamente com a crescente divisão do trabalho e o desenvolvimento das ciências experimentais. Assim, cada vez mais remete para um saber técnico que vai para além da simples experiência e dos saberes práticos, devido ao seu carácter sistémico e ao recurso a conceitos abstractos. O substantivo, que remonta ao século XVI, assumiu, sobretudo, essa segunda conotação: o expert é agora "uma pessoa escolhida pelos seus conhecimentos técnicos e encarregada de realizar exames, observações, avaliações a respeito de um facto, de um tema preciso", ou "um especialista encarregado de resolver um problema técnico". ${ }^{11}$ Assim, o expert opõe-se ao não-especialista, àquele cujo saber não está sistematizado do ponto de vista técnico, ao "leigo", ou seja, àquele "que não é versado numa arte, ciência, técnica ou modo de vida". ${ }^{12}$ Como anteriormente demonstrado, é precisamente enquanto não-especialistas que os cidadãos "comuns" são chamados com mais frequência a intervir, sendo o seu saber de utilizador não formalizado ou o seu bom senso aproveitado para complementar um saber técnico que seria inadequado se estivesse isolado (Röcke, 2005). Esta participação dos leigos inscreve-se na oposição à crescente divisão do trabalho, que tende a limitar a acção do saber não especializado a espaços cada vez mais reduzidos. Contudo, determinados tipos de "expertise dos

\footnotetext{
${ }^{8}$ Poderíamos ainda distinguir uma terceira forma de saber comum, o sentido prático manual, muito mobilizado nas acções de benevolência, desde a festa do bairro à construção de pequenos equipamentos, passando pelas associações culturais.

9 Jacques Trenel, Lexique français-latin. Paris: Belin, 1985.

${ }^{10}$ Le petit Robert. Paris: Dictionnaires Le Robert, 2007.

${ }^{11}$ Ibidem.

${ }^{12}$ Ibidem.
} 
cidadãos" que implicam um saber sistematizado e técnico podem também ser empregues nos processos participativos.

De facto, aí emerge cada vez mais um "saber profissional difuso": os cidadãos que participam enquanto habitantes são também trabalhadores dotados de um saber profissional, que pode ser aplicado no seu trabalho ou fora dele. ${ }^{13}$ Este saber pode ser mobilizado tanto na associação aquando da tomada de decisões, como na realização de projectos adoptados. Encontra-se em figuras típicas, tais como o arquitecto que contesta um projecto de urbanismo, o assistente social que discute as políticas públicas para jovens ou imigrantes, ou o professor que participa nas reuniões de turma como encarregado de educação dos seus filhos. Esta forma de saber tende a evoluir com o desenvolvimento do ensino e de uma "sociedade do conhecimento", sendo que, por sua vez, a sua mobilização acompanha o importante papel desempenhado nos novos movimentos sociais pelas classes médias intelectuais surgidas da modernidade. Tendencialmente, o nível de educação dos cidadãos aumenta e o seu capital cultural e técnico não é, em média, inferior ao das pessoas eleitas (ou não é apreciavelmente menor). No século XIX, nesta perspectiva, o desfasamento era muito maior; Henry Rey colocou a hipótese de que esta evolução contribuía para a perda de legitimidade do sistema representativo. É frequente que determinados participantes sejam, do ponto de vista técnico, tão competentes como os responsáveis oficiais. É pouco provável que esta tendência se inverta, o que contribuirá para baralhar a divisão clássica do trabalho entre representantes e representados. Porém, este saber profissional difuso é distribuído e valorizado de forma desigual: o saber profissional manual tem um peso bem menor do que o saber profissional dos intelectuais, especialmente quando os problemas em causa são de carácter geral. As reuniões participativas têm uma dinâmica bastante diferente quando se realizam nos bairros populares e nos bairros abastados. O poder de intervenção dos indivíduos oriundos das classes intelectuais é, na perspectiva do saber profissional difuso, substancialmente superior ao das classes populares, sendo que tal facto transparece, em especial, nos bairros mistos.

A "expertise por delegação" corresponde a uma outra lógica. Designa os conhecimentos técnicos ou profissionais que resultam da delegação por parte do Estado de determinadas tarefas a associações, ou do reconhecimento por parte do Estado da utilidade pública de certa actividade

${ }^{13}$ Este saber profissional constituía uma instância fundamental das problemáticas de supervisão dos trabalhadores e de auto-gestão na empresa, pelo que seria necessário desenvolver sistematicamente as suas implicações de modo a completar a presente tipologia, centrada nos desenvolvimentos mais recentes. 
associativa. Este movimento pode ser efectuado em direcção a entidades parapúblicas ou semiprofissionais e, neste caso, não se trata de um movimento participativo na acepção própria do termo. No entanto, no caso do desenvolvimento comunitário ou da economia solidária, a dinâmica bottom-up pode ser importante. Supunhamos, por exemplo, que determinadas associações comunitárias norte-americanas são levadas a fazer a auto-gestão do parque da habitação social. O saber que se desenvolve nesse quadro pode ser extremamente eficiente do ponto de vista técnico. O sector associativo é, na verdade, capaz de realizar melhor determinadas tarefas do que o Estado, porque é mais flexível e menos burocrático, porque se apoia mais no saber do utilizador de outros cidadãos ou porque a sua proximidade social e cultural com estes lhe facilita a tarefa. Este tipo de expertise dos cidadãos é, todavia, marcado por uma tensão inerente. Quanto mais os responsáveis associativos se profissionalizam e se tornam experts das pastas que gerem, mais se diferenciam do saber do utilizador dos outros cidadãos, e mais a distância que os separa da sua base tende a aumentar. A divisão entre experts e leigos renasce no próprio interior da "sociedade civil”. Em França, desde há duas ou três décadas que se assiste a uma clara tendência para a profissionalização das associações. Nos Estados Unidos, o sector comunitário transformou-se num meio profissional de gestores associativos que transitam de uma organização comunitária para outra e que são capazes, quando a oportunidade se apresenta, de se reconverterem ao mercado privado. A expertise por delegação tende, assim, a entrar em contradição com uma dinâmica real de empowerment, principalmente porque a retirada do Estado força o sector comunitário a depender, cada vez mais, do mercado, com os imperativos de rentabilidade que isso implica (Bacqué, 2003). Contudo, a crise do Estado-Providência e a crescente externalização de uma série de tarefas tornam provável o desenvolvimento dessa expertise por delegação e, consequentemente, das tensões suscitadas pelo profissionalismo dos líderes associativos e dos dirigentes comunitários, porque não é possível inverter facilmente a divisão do trabalho.

A "contra-análise" assenta numa dinâmica diferente. Tradicionalmente, surge num contexto de controvérsia técnica ou científica, quando determinados actores demonstram a necessidade de abrir o debate e alargá-lo para além do círculo habitual de decisores. As associações que pretendem uma contra-análise podem realizá-las elas próprias ou recorrer a experts externos. Durante as últimas décadas, multiplicaram-se este tipo de exemplos em diversos campos: elaboração de planos de urbanismo alternativos ou de planos comunitários oriundos das bases, o papel da mobilização das associações de doentes na aplicação de novos protocolos ou tratamentos, 
a contestação do cultivo de organismos geneticamente modificados, entre outros. Todos estes factos deram origem a uma literatura abundante e inovadora (Callon et al., 2001; Charvolïn, 2007; Blondiaux e Sintomer, 2002).

A ideia de que o recurso à contra-análise pudesse tornar-se normal em vez de se manter como uma excepção pressupõe uma problemática mais ampla, baseada em três princípios:

1) A sociedade contemporânea é concebida como uma "sociedade de risco" (Beck, 2003) ou um "mundo incerto" (Callon et al., 2001) no qual se toma mais em conta os novos riscos relacionados com a acção humana. As ciências e as técnicas não constituem apenas os elementos que permitem enfrentar os novos problemas, como são também partes interessadas nas causas, e esta tomada de consciência afecta os meios científicos e as classes sociais que emergiram da modernidade. A crise do modelo Fordista de acumulação do capital ou a dimensão das crises ambientais, agora vistas como riscos principais, contribuem para esse desenvolvimento. Já não se pode aceitar como verdade a opinião dos experts, porque estes se enganam frequentemente, porque as soluções que propõem não deixarão de suscitar problemas não previstos, mas também e, principalmente, porque a sua expertise é influenciada por factores culturais ou políticos que estão longe de serem neutros.

2) Ainda que as ciências e as técnicas tenham sido sempre profundamente influenciadas pelos interesses sociais, bem como produto de colaborações entre actores que estavam longe de pertencer apenas aos círculos de cientistas e técnicos, um forte movimento leva actualmente as ciências e as técnicas a encostarem-se mais aos mercados através da modificação dos direitos de patentes, das ligações estabelecidas entre centros de investigação, indústria e capital de risco, do reforço do mercado de diplomas, etc. (Pestre, 2003).

3) Nesta perspectiva, a contra-análise nas mãos dos cidadãos (ou provocada pela sua acção) constitui um elemento indispensável para compensar as lógicas burocráticas e financeiras. Os simples cidadãos e as suas associações tornam-se potenciais actores legítimos numa "democracia técnica", reclamada por um crescente número de grupos (Callon et al., 2001; Charvolin, 2007). Assim, as associações podem realizar contra-análises ou delegá-las em especialistas, e, além disso, ter uma influência sobre a orientação global do conjunto de expertises, sobre as suas modalidades e sobre as escolhas que devem efectuar face às suas conclusões.

Ainda mais do que a expertise por delegação, o recurso à contra-análise é uma dimensão fundamental do "saber do cidadão". Para retomar a imagem utilizada por John Dewey, a contra-análise ultrapassa o saber do utilizador, visto que coloca em questão a delegação da solução técnica ao sapateiro: 
não se trata apenas de lhe explicar onde é que o sapato aperta; já nem é o caso de alguns participantes serem, por seu turno, sapateiros, como no saber profissional difuso, ou que se estabeleça uma associação comunitária que se dedica a reparar os sapatos usados, como na expertise por delegação; a contra-análise pressupõe, recorrendo à mesma metáfora, a realização de vários diagnósticos aos sapatos, a elaboração de diversas soluções para repará-los, ou seja, contribuir para a sua elaboração desde a fase de fabrico. O mercado, as suas técnicas de marketing e os seus inquéritos de satisfação não são, nesta perspectiva, suficientes, já que estão pressionados pelo enfoque na procura que possa ser satisfeita, pelos desejos de rentabilidade a curto prazo e pelas dinâmicas de externalização dos custos induzidos. Porém, o recurso à contra-análise não se encontra isento de dificuldades. Grandes áreas das práticas científicas não conheceram uma dinâmica que se assemelhasse à mobilização dos doentes da SIDA ou às associações de mulheres norte-americanas sobre o tratamento da menopausa, casos emblemáticos que são também exemplos bastante específicos (Gaudillière, 2006). Para que um plano comunitário realmente surtisse efeito, quantos bairros sofreram uma completa transformação da sua forma e da sua população após a realização de operações imobiliárias sem a menor contra-análise? As associações serão realmente capazes de contrabalançar o crescente alinhamento das ciências e técnicas com a economia capitalista, caso os poderes públicos não mudem radicalmente o seu modo de acção e não ofereçam meios institucionais e materiais que permitam que os movimentos sociais realizem sistematicamente (ou mandem realizar) contra-análises?

\section{O ofício do cidadão?}

Aristóteles, que não era um democrata, considerava, mesmo assim, que o homem é por natureza um "animal político". Logo na primeira justificação filosófica da democracia que conhecemos, Protágoras, referindo-se a Atenas, explicava:

Quando é necessário deliberar sobre os assuntos que interessam à administração do Estado, vemos levantarem-se indiferentemente para tomar a palavra arquitectos, ferreiros, sapateiros, comerciantes e marinheiros, ricos e pobres, nobres e pessoas do povo, e ninguém os acusa [...] de ousarem dar conselhos sem terem aprendido nada de nenhuma fonte e sem terem tido nenhum mestre. É que, manifestamente, não consideramos que isso se ensine. ${ }^{14}$

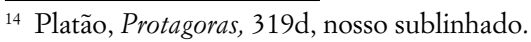


Nesta problemática radical, o bom senso adquire uma dimensão política na pura acepção do termo, deixando de estar restringido ao raciocínio subjectivo sobre questões particulares e permitindo discutir todo o conjunto de problemas da cidade. No entanto, esta concepção dependia de instituições igualitárias e democráticas que só funcionavam porque uma socialização intensiva "treinava" os futuros cidadãos no exercício da autonomia (Castoriadis, 1978), permitindo-lhes confrontarem-se diariamente com as escolhas públicas e, assim, exercerem as suas responsabilidades. Para aqueles que se empenharam totalmente (o que esteve longe de ser o caso com todos os atenienses livres), a cidadania era, nesse sentido, um "ofício", recorrendo à expressão utilizada por Claude Nicolet (1989) a respeito da república romana, e implicava um conhecimento rotineiro de diferentes actividades, desde a participação na Assembleia, ao exercício das diferentes responsabilidades cívicas, passando pelos sorteios ou pela eleição dos magistrados. O saber político que aí se aplicava pressupunha, obviamente, a faculdade de julgamento simbolicamente ligada ao estatuto de cidadão, mas também se baseava numa educação para a cidadania assente na prática quotidiana desta, que conduzia à criação de um quase-ofício. É por isso que a expertise que os cidadãos, supostamente, deveriam demonstrar não estava limitada à sua experiência concreta e podia dizer respeito a temas gerais, precisamente o que Joseph Schumpeter considerou vinte cinco séculos mais tarde fora do alcance do julgamento razoável das massas. Se os experts técnicos fossem regularmente convocados e escutados, caberia à assembleia de cidadãos decidir desbloquear ou não a questão em discussão.

Ora, se o bom senso político, como faculdade do homem ou do cidadão, e a competência política, como saber que resulta de um processo de educação e socialização, se podem articular num círculo virtuoso, também é verdade que podem originar tensões. Tal facto é perceptível através das críticas aristocráticas das democracias antigas que afirmavam que, como a competência política está distribuída de forma desigual, importa partilhar as responsabilidades em função dessa hierarquia. A tensão foi reforçada nas democracias modernas dominadas pelo princípio da representação - e, assim, da delegação da tomada de decisão nas pessoas eleitas, supostamente, na concepção dos pais fundadores, seres mais sábios que os simples cidadãos. Estas democracias desenvolveram uma visão claramente menos intensiva da vita activa que a cidade de Atenas ou mesmo que o humanismo cívico de Florença no final da Idade Média e no início do Renascimento. Longe de ser o apanágio de pensadores conservadores ou liberais, a suspeita de incapacidade que pairava sobre as massas era também fermentada pela esquerda republicana ou socialista - cujas ambivalências sobre a questão do sufrágio 
universal (Rosanvallon, 1992) ou sobre o tema da avant-garde foram reveladoras. A tensão entre "bom senso" político e "ofício" político assume uma dimensão particular a partir do momento em que a política se torna numa profissão. A ideia de que a divisão social do trabalho crescia constantemente e que era normal que a política activa estivesse, como todas as actividades, reservada a um número restrito de indivíduos com formação para esse efeito, estava presente desde a Revolução Francesa. O progressivo surgimento de políticos de profissão, na segunda metade do século XIX, reforçado num segundo momento pela criação dos partidos de massas, representa, porém, uma evolução considerável. Este movimento contrabalança amplamente o lento acesso de todos os indivíduos adultos à cidadania, ao limitá-los ao papel de leigos face aos profissionais da política.

Contudo, no século XIX, só os mais conservadores entendiam que se devia limitar os cidadãos não eleitos à sua esfera privada e negar-lhes qualquer competência política. Um liberal como Benjamin Constant, que defendia com paixão a divisão política do trabalho mediante a qual "uma nação delega em determinados indivíduos aquilo que ela própria não pode ou não quer fazer" (Constant, 1986), aceitava paralelamente que os cidadãos tinham a competência e o dever de verificar se os representantes actuam em prol dos seus melhores interesses. Desde os republicanos aos liberais passando por determinados socialistas, muitos acrescentavam que, a fim de reforçar a legitimidade do Estado, era necessário desenvolver o conhecimento que os cidadãos têm acerca deste e, consequentemente, do funcionamento das instituições, das questões políticas globais e do interesse geral. Nesta perspectiva, o Estado deveria tornar-se num educador - a introdução de escolas públicas e da educação cívica apontavam também neste sentido. É frequentemente nesta perspectiva que a participação de leigos nos tribunais de júris era justificada, porque permitia aos membros da sociedade civil conhecer o direito, exercê-lo e reclamá-lo (Hegel, 1986: \$228; Sintomer, 2007). Algumas décadas mais tarde, Émile Durkheim (1990: 122-126) podia fazer o elogio de uma democracia deliberativa na qual o desenvolvimento da discussão colectiva permite aumentar a consciência social e o conhecimento reflexivo de uma sociedade acerca de si própria, acrescentando ainda que:

o papel do Estado não é o de exprimir, resumir o pensamento irreflectido da multidão, mas sim o de acrescentar a esse pensamento irreflectido um pensamento mais ponderado e, forçosamente, diferente. É, e deve ser, foco de representações novas, originais, as quais devem colocar a sociedade em condições de se conduzir com maior inteligência do que quando esta se move simplesmente pelos sentimentos obscuros que a agitam. 
A intensificação da comunicação entre o Estado e a sociedade, assim como a sua crescente aproximação - características da democracia - segundo Durkheim, não deviam originar confusão: na sua opinião, havia claramente um educador e os educandos. Ainda hoje em dia, muitas vezes é nesse sentido que os dispositivos participativos são implementados ou, pelo menos, que os seus efeitos são considerados positivos pelos responsáveis políticos: eles permitem que os cidadãos tenham uma melhor compreensão acerca dos desafios públicos, do funcionamento do Estado, dos imperativos de gestão ou da dedicação das pessoas eleitas. A cultura cívica assim adquirida possui, antes de mais, uma função de legitimidade. Neste sentido, constitui um tipo de variante política do saber do utilizador anteriormente descrito, que se constrói através do contacto com as instituições. Não releva do bom senso, nem da expertise no sentido profissional do termo. Trata-se de uma iniciação, necessariamente parcial, aos mistérios do ofício político, continuando este a ser apanágio dos profissionais.

O saber político resultante de processos participativos ou, de uma forma mais geral, do envolvimento nos problemas da cidade, pode, todavia, ter um sentido que vai para além deste quadro pedagógico, no qual a divisão do trabalho entre aqueles que sabem e aqueles que aprendem parece manter-se intacta. Nas experiências mais radicais, a ideia da participação como "escola de cidadania" remete para uma democracia participativa no sentido estrito do termo, ou seja, uma combinação entre as instituições da democracia representativa e as dimensões da democracia directa. A escola em questão visa emancipar os cidadãos e conceder-lhes um saber que lhes permite, progressivamente, renunciar à tutela das pessoas eleitas. Permite-lhes atingir mais facilmente os seus fins quando se confrontam com as autoridades. Ainda que o saber em questão assente, em parte, num saber do utilizador que resulta da experiência do contacto com as instituições, inclui também formas de expertise por delegação e de contra-análise que alimentam a formação dos contra-poderes (Fung e Wright, 2005). Este já era o raciocínio de Karl Marx (que, analisando a dinâmica da democracia representativa, escreveu:

O regime parlamentar vive do debate; como pode proibir os debates? Cada interesse, cada instituição social é transformada aqui em ideias gerais, debatidas como ideias. Como pode qualquer interesse, qualquer instituição, afirmar-se acima do pensamento e impor-se como artigo de fée [...] Os representantes, que apelam constantemente à opinião pública, dão à opinião pública o direito de expressar a sua verdadeira opinião. [...] Quando se toca música nas altas esferas do Estado, o que se pode esperar dos que estão em baixo se não que dancem?" (Marx, 1984) 
Era também a lógica partilhada por Alexis de Tocqueville quando reflectia sobre o impacto dos jurados na América do século XIX. Tocqueville coincidia com Hegel no elogio das repercussões pedagógicas dos júris constituídos por cidadãos. Contudo, na sua opinião, não se tratava apenas do facto de a sociedade civil compreender melhor as necessidades e regras do Estado, mas mais de valorizar uma instituição "republicana", "na medida em que coloca o rumo real da sociedade nas mãos dos governados ou de uma parte dos mesmos, e não na dos governantes". Assim podia concluir solenemente que "o júri, que é o meio mais firme de fazer o povo reinar, é também o meio mais eficaz de o ensinar a reinar" (Tocqueville, 1981: Livro I, parte V). Tal problemática foi amplamente retomada nas correntes participativas contemporâneas, de Carole Pateman (1970) a C. B. Macpherson (1977), passando por Tarso Genro e Ubiratan De Souza (1998). À imagem do mundo antigo, assiste-se ao reflorescer do "ofício de cidadão" e ao declínio do "fetichismo da delegação política" (Pierre Bourdieu). Nas abordagens mais radicais, de inspiração marxista ou anarquista, a divisão social faria da política um ofício que acabaria por se esfumar.

De acordo com as lições dos historiadores de cidades antigas, medievais e renascentistas, a análise sociológica das experiências contemporâneas de democracia participativa, incluindo as mais radicais, impele, porém, a duvidar da relevância da reabsorção do saber dos profissionais da política num saber político mais geral. A participação só diz respeito, no melhor dos casos, a uma pequena minoria de cidadãos, assim como é extremamente desigual do ponto de vista social, sendo que os que se dedicam mais tendem a tornar-se, por sua vez, profissionais da política - profissionais ao serviço dos movimentos sociais, ONGs ou associações comunitárias, mas, de qualquer forma, profissionais, cujo tipo de saber, por vezes, se assemelha mais ao dos políticos e altos funcionários que contestam, do que aos das suas bases. Como tal, as visões elitistas (sociológicas ou políticas) que consideram que o desenvolvimento dos processos participativos ou novos movimentos sociais não são mais do que uma ilusão que reproduz a estruturação da política como mercado, com uma "oferta" na qual os profissionais (estabelecidos ou contestatários) teriam o monopólio e uma "procura" à qual estariam cingidos os cidadãos leigos, passam ao lado de evoluções bem reais. A "intervenção" (voice) participativa dificilmente se deixa reduzir à dicotomia oferta/procura. Incarna mais uma tendência que contrabalança, pelo menos em parte, a divisão política do trabalho entre um domínio que resultaria do saber de profissionais e um domínio que resultaria (na melhor das hipóteses) do saber do utilizador ou do bom senso dos leigos. 
Em meados dos anos 80, Claus Offe (1997) defendeu a "utopia da opção zero": uma menor diferenciação social (a "opção zero") poderia, num determinado número de circunstâncias, demonstrar ser mais racional do que uma diferenciação levada ao extremo. O actual desenvolvimento dos "saberes dos cidadãos" leva a retomar e a esmiuçar esta problemática, sendo que podem ser avançadas várias hipóteses:

1) Na linha de John Dewey, importa sublinhar que o crescente recurso ao saber do utilizador tende a relativizar o corte entre saber profissional/saber leigo: a eficácia do saber técnico assenta, em grande medida, numa colaboração com o saber do utilizador.

2) O recurso ao bom senso mostra simultaneamente que uma parte importante da decisão escapa a uma definição puramente técnica e implica escolhas culturais, sociais ou políticas - escolhas às quais os cidadãos comuns podem razoavelmente estar associados, desde que haja um procedimento adequado que thes permita dispor de informações suficientes e reflectir apropriadamente sobre a questão.

3) O desenvolvimento do saber profissional difuso, que caracteriza as sociedades do conhecimento, tende a diluir os papéis e a confrontar os saberes técnicos das pessoas que ocupam os cargos oficiais com os saberes também técnicos dos "simples" cidadãos.

4) Se é verdade que o desenvolvimento da expertise por delegação, que implica as associações da sociedade civil, cria novas tensões, não é menos verdade que também relativiza a divisão do trabalho político que tem por objectivo instaurar um continuum que vai do simples envolvimento benévolo à constituição de associações comunitárias bastante profissionais.

5) O recurso à contra-análise, que se torna menos raro, testemunha o regresso das sociedades contemporâneas à reflexão sobre o papel das ciências e das técnicas; abre a porta a uma "democracia técnica" que, em determinados sectores, já conduziu a resultados que não são negligenciáveis.

6) Nestas condições, o desenvolvimento de um saber político através das "escolas de democracia", que são os movimentos sociais ou os dispositivos participativos mais dinâmicos, pode ser chamado a desempenhar um papel relevante. Este desenvolvimento não conduzirá ao desaparecimento dos políticos profissionais às custas do "ofício do cidadão" na antiga acepção do termo. Não se reduz, como tal, a uma cultura cívica instrumental para a legitimação das autoridades e poderia multiplicar as situações nas quais os cidadãos "desempenham o papel dos políticos".

De resto, as tensões inerentes aos "saberes dos cidadãos" não são também elas, pelo menos em parte, próprias da política no seu conjunto? O saber próprio de quem faz da política profissão avalia-se, principalmente, através 
da habilidade estratégica e táctica empregue nas lutas de poder, sem a qual uma personalidade não se pode impor no jogo político. Trata-se, inequivocamente, do saber mais específico dessa profissão, mas, isolado, produziria apenas políticos na acepção negativa do termo. O saber político profissional implica, igualmente, um savoir-faire na gestão das políticas públicas e um domínio dos dossiers técnicos - que faz com que a política não se reduza à pura demagogia e que se possa articular com uma verdadeira racionalidade da acção pública. Mesmo assim, face aos experts profissionais e administrativos, os responsáveis políticos devem recorrer a outros meios epistemológicos e demonstrar a sua capacidade para conduzir a acção colectiva (ou a estar em sintonia com ela) e para chamar a atenção para os desafios políticos dos dossiers técnicos, de modo a ir além do tecnocratismo e combinar a gestão do presente com a defesa das grandes causas ético-políticas (Weber, 2003). Neste sentido, se aqueles e aquelas que se dedicam ao ofício da política se puderem apoiar numa expertise própria, não será que esta deve ser entendida na acepção neolatina do termo - "tornado hábil pela experiência” - em vez de na acepção restritiva de uma competência profissional ou científica? Deste ponto de vista, não existe um corte epistemológico, mas apenas uma diferença de grau entre este tipo de saber político e o dos "leigos". Este desfasamento está longe de poder sustentar só por si a monopolização do poder pelas pessoas eleitas que a história impôs. Assim, não será possível relativizar esta monopolização através de outras construções sociais e políticas? A introdução de regras a respeito da acumulação de mandatos, o financiamento dos partidos políticos e das associações, o funcionamento dos meios de comunicação social ou o desenvolvimento dos dispositivos participativos são susceptíveis de aumentar consideravelmente o número de pessoas que dispõe de uma cultura cívica. Mesmo que continuem, muito provavelmente, bastante desiguais do ponto de vista social, será que estes desenvolvimentos não poderão contribuir para credibilizar a política no seu todo?

\section{Referências bibliográficas}

Abramson, Jeffrey (2003), We the Jury, The Jury System and the Ideal of Democracy. Cambridge/London: Harvard University Press [ $3^{a}$ ed.].

Bacqué, Marie-Hélène (2003), "Les nouvelles figures des quartiers populaires, politiques et représentations. Une approche comparative France/Etats-Unis”. Relatório de habilitação para coordenar projectos de investigação, Université Paris XII.

Beck, Ulrich (2003), La société du risque. Tradução do alemão de Laure Bernardi. Col. Champs. Paris: Flammarion. 
Blondiaux, Loïc; Sintomer, Yves (orgs.) (2002), “Dossier Démocratie et délibération”, Politix, 57.

Callon, Michel; Lascoumes, Pierre; Barthe, Yannick (2001), Agir dans un monde incertain. Essai sur la démocratie technique. Paris, Seuil.

Castoriadis, Cornélius (1978), Les carrefours du labyrinthe. Paris: Seuil.

Cefaï, Daniel; Trom, Danny (orgs.) (2001), Les formes de l'action collective. Paris: Éditions de l'EHESS.

Charvolï, Florlan (org.) (2007), Des sciences citoyennes? La question de l'amateur dans les sciences naturalistes. La Tour d'Aiguës: Ed. de l'Aube.

Constant, Benjamin (1986), "De la liberté des anciens comparée à celle des modernes" [1819], De l'esprit de conquête et de l'usurpation. Paris: Flammarion.

Dewey, John (1954), The Public and lts Problems. Athens: Swallow Press/Ohio University Press [11927].

Durkheim, Émile (1990), Leçons de sociologie. Paris: PUF [11950].

Foucault, Michel (1994), “Cours du 7 janvier 1976”, Dits et Ecrits III. Paris: Gallimard.

Fung, Archon; Wright, Erik Olin (2005), "Le contre-pouvoir dans la démocratie participative et délibérative”, in Marie-Hélène Bacqué, Henri Rey e Yves Sintomer (orgs.), Gestion de proximité et démocratie participative: une perspective comparative. Paris: La Découverte, 49-80.

Gaudillière, Jean-Paul (2006), La médecine et les sciences, XIXe-XXe siècles. Paris: La Découverte.

Genro, Tarso; De Souza, Ubiratan (1998), Quand les babitants gèrent vraiment leur ville. Le Budget Participatif: l'expérience de Porto Alegre au Brésil. Trad. do português de Eliana Costa Guerra, Jean-Biaise Picheral e Martine Toulotte. Paris: Fondation Charles Léopold Meyer.

Hegel, Georg Wilhelm Friedrich (1975), La société civile bourgeoise. Apresentação e trad. de Jean-Pierre Lefèbvre, com a colaboração de Michèle Jalley, Béatrice Avakyan-Ryng e Marie-Thérèse Aoudaï. Paris: Maspéro.

Hegel, Georg Wilhelm Friedrich (1986), Principes de la philosopbie du droit [1821]. Tradução do alemão de Robert Derathé. Paris: Vrin.

Macpherson, C. B. (1977), The Life and Times of Liberal Democracy. Oxford: Oxford University Press.

Manin, Bernard (1995), Principes du gouvernement représentatif. Paris: Calmann-Lévy.

Marx, Karl (1984), Le 18 Brumaire de Louis-Napoléon Bonaparte [1852]. Paris: Messidor/ Éditions Sociales.

Nicolet, Claude (1989), Le métier de citoyen dans la Rome républicaine. Paris: Gallimard ( $2^{\mathrm{a}}$ ed.).

Offe, Claus (1997), Les démocraties modernes à l'épreuve. Tradução do alemão de Yves Sintomer e Didier Le Saout. Paris: L'Harmattan. 
Pateman, Carole (1970), Participation and Democratic Theory. Cambridge: Cambridge University Press.

Pestre, Dominique (2003), Science, argent et politique: un essai d'interprétation. Paris: INRA Editions.

Röcke, Anja (2005), Losverfabren und Demokratie: Historische und Demokratietheoretische Perspektiven. Münster: LIT Verlag.

Rosanvallon, Pierre (1992), Le sacre du citoyen. Paris: Gallimard.

Rosanvallon, Pierre (1998), Le peuple introuvable. Histoire de la représentation démocratique en France. Paris: Gallimard.

Rousseau, Jean-Jacques (1964), Le contrat social. CEuvres complètes, III. Paris: Gallimard. Schumpeter, Joseph A. (1946), Capitalism, Socialism and Democracy. London/New York: Harper \& Row.

Sintomer, Yves (2007), Le pouvoir au peuple. Jurys citoyens, tirage au sort et démocratie participative. Paris: La Découverte.

Tocqueville, Alexis de (1981), De la démocratie en Amérique. Livro I. Paris: Garnier Flammarion [1835-1840].

Weber, Max (2003), Le savant et le politique. Tradução do alemão de Catherine Colliot-Thélène. Paris: La Découverte [1919]. 